\title{
Retraction Note: Short-term rainfall monitoring in mountainous area based on Bayesian model and mental health intervention of college students
}

\section{Xiushan $\mathrm{Li}^{1}$}

Published online: 18 November 2021

(c) Saudi Society for Geosciences 2021

Retraction Note: Arabian Journal of Geosciences (2021) 14: 1579 https://doi.org/10.1007/s12517-021-08010-5

The Editor-in-Chief and the Publisher have retracted this article because the content of this article is nonsensical. The peer review process was not carried out in accordance with the Publisher's peer review policy. The author has not responded to correspondence regarding this retraction.

The original article can be found online at https://doi.org/10.1007/ s12517-021-08010-5

Xiushan Li

xiushanli123@126.com

1 Institute of Traffic Engineering, Nanjing Vocational

University of Industry Technology, Nanjing 210000, Jiangsu,

China 